\title{
Microorganisms: Integrating Augmented Reality and Gamification in a Learning Tool
}

\author{
Ratna Zuarni Ramli ${ }^{1}$ \\ Faculty of Computer and Mathematical Science \\ Universiti Teknologi MARA \\ Kuala Pilah, Malaysia
}

\author{
Nor Athirah Umairah Marobi ${ }^{2}$ \\ Noraidah Sahari@Ashaari ${ }^{3}$ \\ Faculty of Information Science and Technology \\ Universiti Kebangsaan Malaysia, Bangi Malaysia
}

\begin{abstract}
Microorganisms is a Year 6 Science subject that primary school students find considerably less attractive because of the enormous facts that require them to have good imaginary skills to understand. Only limited applications are available on smartphones as tools to learn subjects, especially Science, Technology, Engineering and Mathematics (STEM). Since the young generation is very much into current technology, there is a need to develop an application to gain students' interest and improve their understanding of microorganisms. Therefore, a microorganism learning application that combines augmented reality (AR) and gamification called Microorganisms was developed. The Microorganisms prototype includes two modules; learning and training. The learning modules use AR technology that scan marker images to display a digital layer of microorganisms in three dimensions (3D). Meanwhile, the training module is represented through gamification consisting of quiz questions, a timer, and a score. The application was designed using Agile methodology and developed using various software such as Unity, Autodesk 3ds Max, Vuforia, and Firebase. Ten respondents, nine students and one teacher in a primary school, assessed the prototype through experimental testing. The results showed that, on average, the user satisfaction value was 4.6 out of 5 . Thus, the Microorganisms application based on AR and gamification can be considered a good learning tool for primary school students to learn about micro-organisms.
\end{abstract}

Keywords-Augmented reality; digital game-based learning (DGBL); game; learning tool; microorganisms; usability testing

\section{INTRODUCTION}

Students have been learning the Science subject from a young age, not only as a requirement in school but also for student comprehension. Microorganisms are one of the subtopics that Year 6 students learn in primary school. The students need to realise that microorganisms, such as viruses, are tiny and can only be seen through a microscope and cannot be seen with the naked eye. This concept becomes more difficult for students to understand and appreciate the design and structure of the microorganism itself. Most students and even parents consider that the Science subject or field is not easy to understand [1]. Moreover, scientific notes are dense with writing and facts, which causes students to lose interest in learning and understanding the topic of microorganisms. Thus, it is essential to create a learning tool that can grab students' attention and realise that Science is an exciting subject to learn. Factors that can motivate students to learn include presenting the content in various ways, such as sound, visualisation, and animation [2]. Specifically, it is more stimulating for the students to get to see the microorganisms in 3D.

Augmented reality (AR) is a current technological medium that offers a unique opportunity that combines the physical and virtual worlds [3]. AR works interactively and in real-time, aligns real and virtual objects [4]. Many applications relating to education have applied AR in their design. For example, the AR Marine Scientific program aims to create awareness of marine environments among lower-grade primary school students. It was identified that the application could help low academic achievers improve their learning performance [5]. Besides, AR (as a learning supplement) has also been used in research to evaluate and compare Biology students learning via AR and printed books, in which it was found that both methods indeed helped enhance the learning of Biology [6]. Furthermore, some AR applications include a game element to attract learners' attention. Gaming is significantly related to the young generation, which generally consists of avid gamers. Therefore, a good learning tool that combines AR technology and gamification in the application design may help students learn better [7].

Thus, this research aims to design and develop an application as a learning tool to learn the microorganism topic, especially for primary school students, with the integration of AR technology and gamification in the design. First, this research paper discusses the current tools in the market for learning the Microorganism topic and the AR applications that have been developed by other researchers in a similar area, followed by the present research methodology, including the framework and the development of the Microorganism application prototype. Sections 3 to 6 discuss the process of evaluating the application, Microorganisms. Finally, the paper reviews the evaluation results and discusses the development of the Microorganisms application.

\section{LEARNING TOOL FOR MiCROORGANISMS}

Learning Science subjects can be frustrating for some people because they cannot see or imagine how certain scientific phenomena work. Hence, many learning tools have been created to help enhance learning activities, especially science subjects or topics. Some tool designs may suit particular aims and can be used by others facing similar issues in learning.

One study compared the learning performance between students learning biology using an AR application and a 
printed book [6]. Their study showed no difference in understanding and remembering factors between the students in both categories. However, the students that used the AR application showed a better learning attitude than the students who used printed books. However, the study gave no detailed explanation of the application design.

Meanwhile, another work [8] proposed a visual aid for students and practitioners to learn about antimicrobials in Microorganisms in the form of a video. The support was aimed at adult learners, and based on the result analysis, the tool indeed helped improve user understanding. Moreover, the video presentation is an excellent method to assist students in learning the topic. Nevertheless, it can still be improved by using 3D or even four dimensions so that the organism could be seen from a different angle.

Another study created a learning tool for Microorganisms specifically to learn the mushroom structure. The study applied AR technology to display the design in 3D [9]. Based on the evaluation process, it was identified that the tool offered a reasonable satisfaction rate among users. Nevertheless, the application focused on AR and did not include any game element in the design. Also, the application content is not similar to the primary school syllabus in Malaysia. Still, it can be used as a reference for local students to learn the topic beyond that covered in school.

Applications with AR features have been developed since the 2000s. Many AR applications help students to improve their learning performance, especially in subjects considered challenging or less interesting; for example, ATHYNOS, a serious AR game for children with Dyscalculia, was developed to help them learn mathematics. ATHYNOS was identified to be able to help students with calculation disorders and, based on the evaluation results, the students took less time to understand the subject [10]. Another application was also designed and developed to learn Kanji, considered one of the most challenging writing systems. Called Dragon Tale, the adventure game with AR features was designed to help students learn Kanji interactively [11]. Similar research also aimed to help students in Thailand to learn the same writing system [12]. Hence, the study designed an AR application that improved Kanji skills by more than $41 \%$.

According to some studies [6], [8], [9], a learning application should consider including multiple media to attract students' attention, such as video, audio, graphic, text and animation. The lengthy and dense text should be avoided as much as possible. The element of 3D that is activated through AR features can be one of the fun factors in learning [13]. It is also essential to assess the student's comprehension; thus, questions or quizzes should be attached at each lesson in the application [6], [8], [14]. Since gaming is very much connected to the young generation, the assessment can be presented in a game where students can compete with other players. The current problem is identified based on real scenarios at local schools where students are having a tough time learning the subject. Since there are limited learning materials that suit the syllabus, a research project is conducted to develop a learning application for primary school students to learn Microbiology.

\section{METHODOLOGY}

The research methodology was divided into three main phases: 1) Conceptual, 2) Design and Development, and 3) Evaluation. The conceptual phase involved the process of analysing the current problems and project requirements. The second phase, Design and Development, comprised designing the application and developing the prototype. At the same time, the last phase involved evaluating the prototype and verifying the application design. The overall research method was adapted from the agile methodology that is usually applied in software development. In mobile software engineering, this methodology is essential since the software is constantly changing and evolving based on users' immediate needs [15]. Table I shows the phases and research activities for this study.

In phase 1 , current issues are identified and based on past studies, the essential elements are recognised. Thus, the elements that are included in the application are multimedia like text, graphic, audio, video and animation in 3D. The application also includes AR and gaming feature as fun factors to draw students' interest.

In phase 2, the application is design and developed using multiple software and briefly describe in the following subtopic. While in phase 3 , the process of evaluation is discussed concisely in Section IV.

\section{A. Framework}

There are two modules in the Microorganisms application, learning and training, which are indirectly interconnected. The student can browse through the learning modules or choose to answer questions in the training modules at any time. The learning module is aimed to represent the content of Microorganisms in 3D with the support of Augmented Reality technology. Five topics were included in the learning modules: Fungi, Bacteria, Viruses, Protozoa, and Algae. Students can choose any topic to learn by clicking on the listed buttons labelled with the topic's name. In addition, a button labelled AR is also included in each topic to represent the content of the specific topic in 3D. The student must scan a specialised marker to activate the AR function. Besides, a video presentation of each topic is also included in the learning module.

TABLE I. RESEARCH ACTIVITY

\begin{tabular}{|l|l|l|}
\hline Phase & Research Activity & Output \\
\hline 1. Conceptual & $\begin{array}{l}\text { Analyse the current problem } \\
\text { Get initial information from primary school } \\
\text { teachers and parents } \\
\text { Analyse similar studies }\end{array}$ & Component \\
\hline $\begin{array}{l}\text { 2. Design and } \\
\text { Development }\end{array}$ & $\begin{array}{l}\text { Design the proposed framework } \\
\text { Identify software requirements } \\
\text { Develop the application prototype }\end{array}$ & $\begin{array}{l}\text { Application } \\
\text { prototype }\end{array}$ \\
\hline 3. Evaluation & $\begin{array}{l}\text { Functional testing } \\
\text { Usability testing }\end{array}$ & $\begin{array}{l}\text { Verified } \\
\text { application } \\
\text { framework }\end{array}$ \\
\hline
\end{tabular}


The training module is aimed at testing student knowledge on the same topics as the learning module. In the training module, some questions are grouped into four difficulty levels to imitate the gamification structure. The students are given a time limit to answer the questions, and at the end of the training session, the student's individual score is displayed together with their ranking. Fig. 1 shows the application framework for Microorganisms.

The application prototype for Microorganisms was designed based on an application framework. Adobe Photoshop and Unity software were used to create the application interface design. Meanwhile, 3D models for the Augmented Reality modules were developed using Autodesk 3ds Max software. The Firebase database was used to store user data and the scores obtained in the training module. The languages used to program the application were C\# and PHP. Fig. 2 to Fig. 9 shows the interface design for Microorganisms.

\section{B. Prototype}

The application prototype for Microorganisms was designed based on an application framework. Adobe Photoshop and Unity software were used to create the application interface design. Meanwhile, 3D models for the Augmented Reality modules were developed using Autodesk 3ds Max software. The Firebase database was used to store user data and the scores obtained in the training module. The languages used to program the application were C\# and PHP. Fig. 2 to Fig. 9 show the interface design for Microorganisms.

Fig. 2 shows the main page of the application that consists of three buttons, Masuk (Login), Tetapan (Settings), and Keluar (Exit) buttons. Users need to select the login button to go to the category selection page. Users can also choose the settings button to set the voice settings and see the how-to-play guide while pressing the exit button to stop the application.

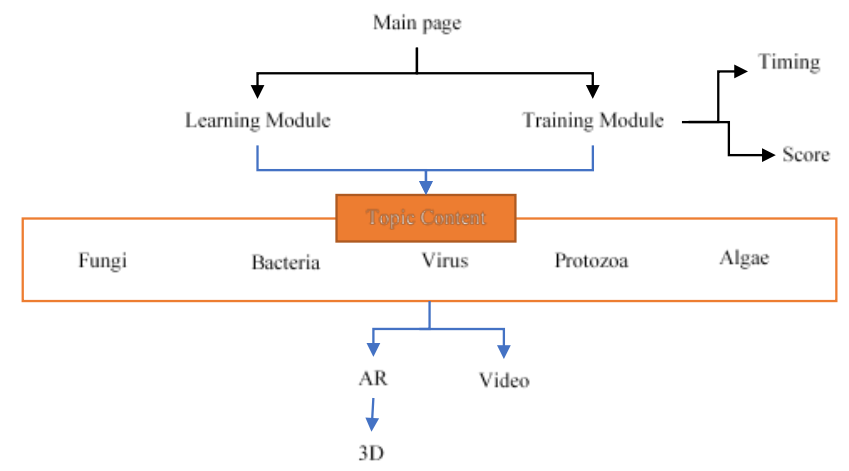

Fig. 1. Application Framework.

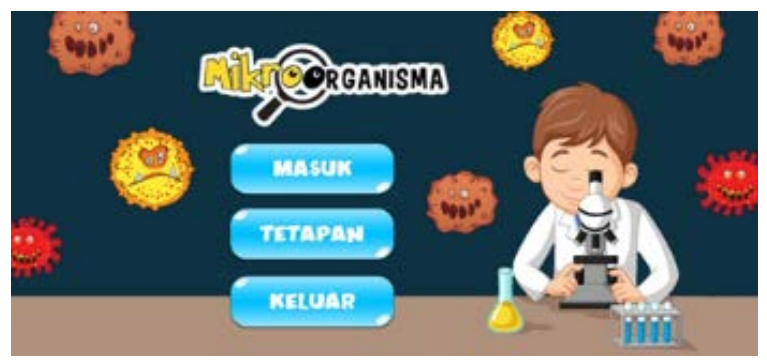

Fig. 2. Main Page.
Fig. 3 shows the category page where users can select the Belajar (Note) button to view notes related to Microorganisms or the Kuiz (Quiz) button to answer quizzes. Users are also allowed to return to the main page by clicking the home button at the top of the page.

Fig. 4 shows the Notes page where the users can select the Fungi, Bacteria, Viruses, Protozoa, and Algae buttons to view notes related to the chosen type of microorganism. There are also buttons for Jenis (Type), Proses Hidup (Processes), Kegunaan (Uses), Keburukan (Disadvantages), and Pencegahan (Prevention). Users can also view the 3D model in AR by clicking on the AR button. There is also a back button to return to the category selection page.

Fig. 5 shows a video page with similar buttons in the Notes page to allow users to view related video descriptions in video format. There is also a back button to return to the category selection page.

The application can access the users' camera to allow users to scan the designed marker. Fig. 6 shows the page that displays the 3D model where users can select the Fungi, Bacteria, Viruses, Protozoa and Algae buttons to view 3D models related to the chosen type of microorganism. There is also a back button to return to the Notes page.

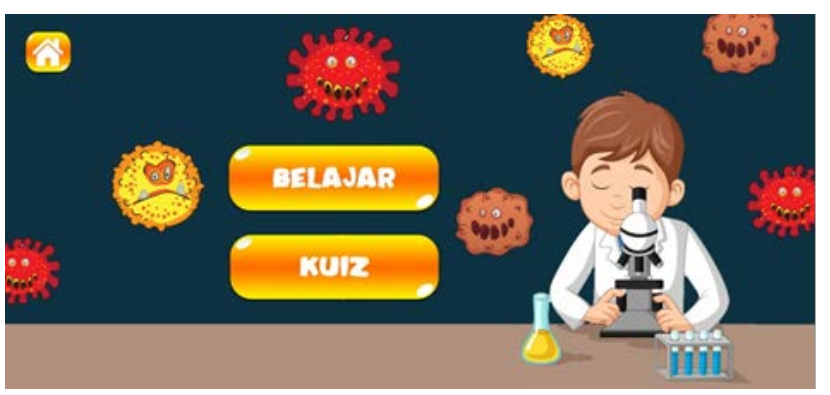

Fig. 3. Category Page.

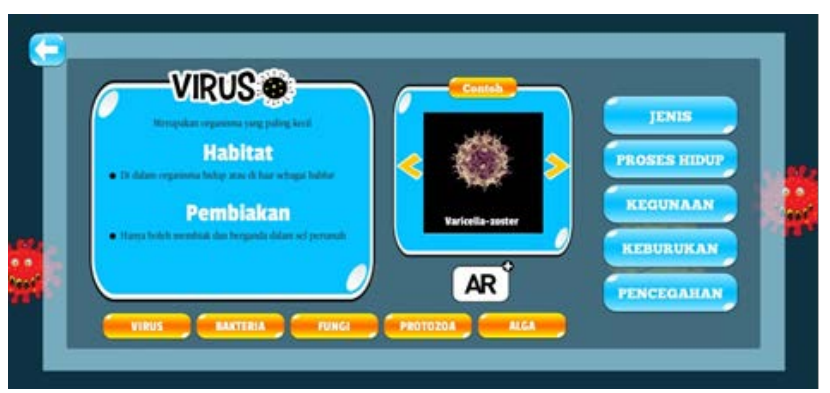

Fig. 4. Notes Page.

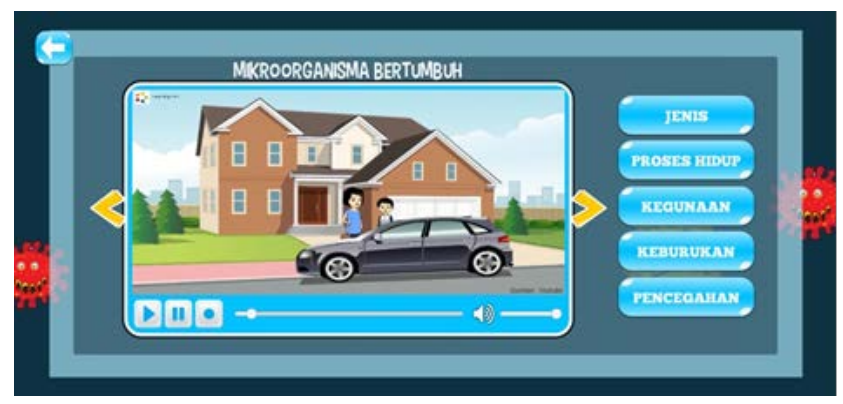

Fig. 5. Video Page. 


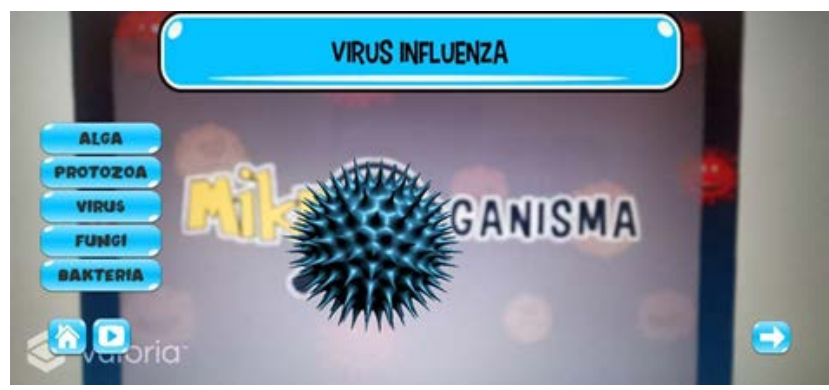

Fig. 6. 3D Model in Augmented Reality.

Fig. 7 shows the game level where users have to answer the quiz questions in order to move to a higher rank.

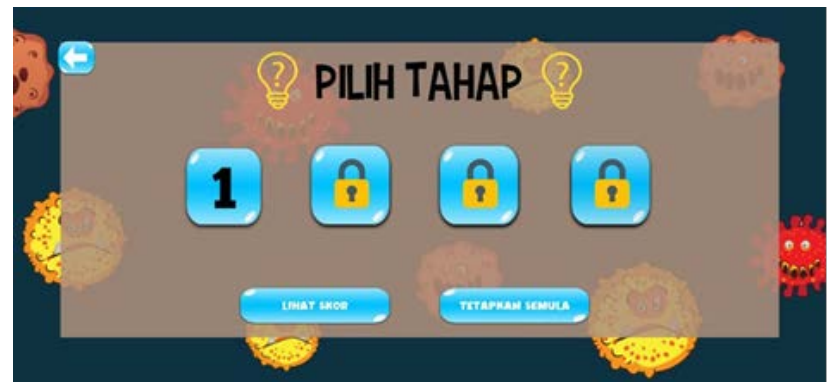

Fig. 7. Level of Difficulties in the Game.

There is a score on the left side of each question. All questions are multiple-choice, like in Fig. 8. There is a time limit to answer each question.
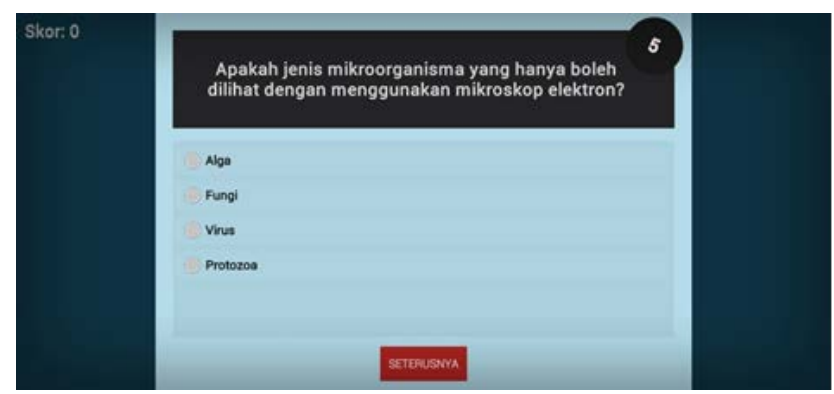

Fig. 8. Example of Quiz.

Fig. 9 shows the scoreboard page to displays the five highest user scores in ascending order.

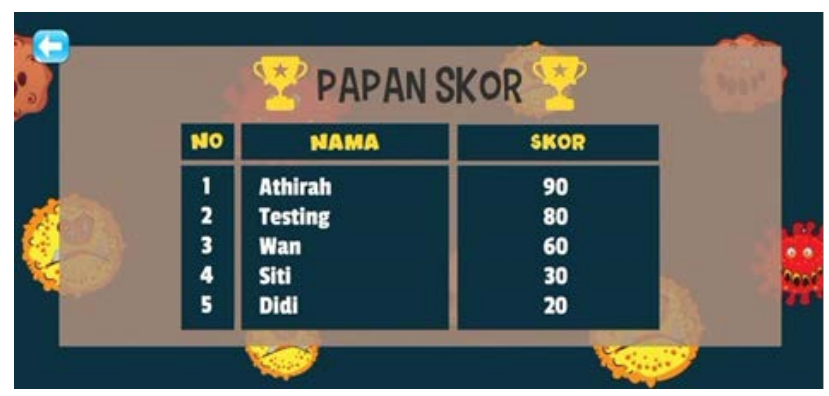

Fig. 9. Scoreboard.

\section{EVALUATION}

Evaluation was conducted via two sets of questionnaires to obtain feedback from the users of the Microorganisms application. The testing process involved ten respondents, consisting of nine students and one Science teacher. The questionnaire consisted of three parts: to test the function of the application and a non-functional variable, usability.

\section{A. Functional Testing}

In functional testing, Microorganism was tested to identify any problems in operating the application. The functions in the learning modules, including browsing the content using the buttons, the scan markers to test the AR function, and watching the $3 \mathrm{D}$ and video content, were tested. Meanwhile, in the training modules, the testing was done by browsing through the game questions of different difficulties, answering some questions, and getting feedback and the game score. Functional testing was done via a simple walkthrough method to ensure that all features such as the buttons, notes, video, 3D model, and AR marker worked well. Four significant phases were included in the functional testing, as described in Table II, while Table III shows one of the detailed procedures in the functional testing. The functional testing procedure was adapted from a past study [16]. Each team member in the project did the testing. No issue was found in all four phases of functional testing. The status column in Table II indicates a pass to show that the application features are working well.

TABLE II. Phases In FunCtional TESTING

\begin{tabular}{|l|l|l|l|}
\hline Phase & Description & Process & Status \\
\hline 1 & Display notes and video & Manual & Pass \\
\hline 2 & Display 3D model & Manual & Pass \\
\hline 3 & Play game & Manual & Pass \\
\hline 4 & Display scoreboard & Manual & Pass \\
\hline
\end{tabular}

TABLE III. EXAMPlE OF DETAILED FunCtionAl TESTING PROCEDURE IN PHASE 2

\begin{tabular}{|l|l|}
\hline Criterion & Description \\
\hline Objective & $\begin{array}{l}\text { To ensure the 3D module works well. It tests whether an } \\
\text { application can display a 3D model of the microorganism } \\
\text { and respond correctly to user interactions. }\end{array}$ \\
\hline Pre-requirement & Markers for AR for users to scan. \\
\hline Testing & $\begin{array}{l}\text { 1. Install the application on a mobile device. } \\
\text { 2. Run the application. } \\
\text { Procedure } \\
\text { the learn and quiz menu page. } \\
\text { 4. Select the "Learn" button - The application displays } \\
\text { the learning notes page. } \\
\text { 5. Select the "AR" button available on each type of } \\
\text { microorganism - The application displays the camera } \\
\text { mode. } \\
\text { 6. Scan the marker image as a target image - The } \\
\text { application displays the model and name of the } \\
\text { microorganism. }\end{array}$ \\
\hline Exit steps & $\begin{array}{l}\text { 1. Press the home button. } \\
\text { 2. The application returns to the main page. } \\
\text { 3. Press the "Exit" button. }\end{array}$ \\
\hline
\end{tabular}




\section{B. Usability and Effectiveness Evaluation}

Ten respondents were asked to evaluate the application and then answer a set of questions using a Likert scale to assess the usability of the Microorganisms application. According to [17], responses from five to ten participants are enough in experimental evaluation. The testing was conducted via an online medium to obtain feedback from the respondents about the usability of Microorganisms. Then, apk files were uploaded onto Google Drive and the URL distributed to the respondents. Feedback from the respondents was collected via Google Forms online questionnaire. The usability evaluation was done to ensure that the application is in line with what users want by observing how users use the application. There are ten questions in total, with the items adapted from a past study [18]. Based on the descriptive analysis, the total mean value for usability was 4.26 and 4.56 for effectiveness. The detail of the usability and effectiveness result is shown in Table IV.

TABLE IV. USABILITY AND EFFECTIVENESS RESULT

\begin{tabular}{|l|l|l|l|}
\hline No. & Factor & Item & Mean \\
\hline 1 & Usability & User-friendly & 4.3 \\
\hline 2 & Usability & Clear instruction & 4.5 \\
\hline 3 & Usability & Easy to use & 3.9 \\
\hline 4 & Usability & Button works well & 4.2 \\
\hline 5 & Usability & Attractive interface & 4.4 \\
\hline 6 & Effectiveness & Easy to understand & 4.4 \\
\hline 7 & Effectiveness & AR is interesting & 4.5 \\
\hline 8 & Effectiveness & Questions in quizzes are understandable & 4.5 \\
\hline 9 & Effectiveness & Enjoyable & 4.8 \\
\hline 10 & Effectiveness & Suitable & 4.6 \\
\hline
\end{tabular}

\section{DisCUSSION AND CONCLUSION}

The initiative to begin the research project came from a teacher in a local primary school who had trouble teaching the microorganism topic. The teacher had problems showing the details of the microorganism to students since the school had no lab equipment. Reference books were the only resource and non-interactive, so it wasn't easy to attract students' interest in learning the topic. Thus, Microorganisms' application was developed as a learning tool to help the students understand the topic and the teacher to teach the subject. It was purposely developed in a mobile platform since most of the students' parents have mobile gadgets that the students can use not only at school or with the teacher but anywhere. The teacher specifically prepared the content of the notes, and the representation of the notes was redesigned by the researcher with the teacher's approval and verification.

To make the notes more interesting, visualising the topic can be a good method to apply [19]. Thus, features of AR and 3D models were added to the mobile application. These features have been identified to hold students' attention in the subject matter [11], [12], [20], [21]. The researchers argued that AR with 3D models creates new experiences and provides new teaching methods, learning, and research [13], [21].
Hence, the AR feature with a 3D model was designed as part of the application to grasp students' attention and interest to learn the topic. Since the topic is part of Science, Technology, Engineering and Mathematics (STEM), the application can also be considered as one of the initiatives to expose students to STEM concepts based on real-world situations.

Designing for a generation exposed to current technology and addiction, gamification has now become a compulsory element in learning tools [22]. Many learning tools that integrate gaming elements in their content aim to increase enjoyment in learning and measure student comprehension of the subject [10], [11]. Also, some studies emphasised the vital role of games in knowledge acquisition and content understanding [14], [22]. The study found that many learning tools have succeeded in delivering knowledge by incorporating gaming into their devices. Consequently, Microorganisms was developed with $\mathrm{AR}$ and layering of $3 \mathrm{D}$ models, with game element integration.

The process of designing and developing Microorganisms took seven months, while another three months were required to evaluate its features, usability, and effectiveness. The evaluation of the application features, known as functional testing, was done via a simple walkthrough method, while the evaluation of usability and effectiveness was done via an online questionnaire. Based on the results of the assessments, the Microorganisms application received good feedback from all respondents, with high mean values for all items. Therefore, this application can be used in class as a learning tool for teachers to teach their students the same topic.

There are some limitations to this research project; firstly, many respondents are negligible due to an imbalance in the number of students and teachers. In the future, the number of respondents will be increased to balance between both types of users (student and teacher). Secondly, the set of questions used to evaluate Microorganisms' usability is simple, so the researchers were unable to obtain detailed feedback from the respondents that could have further enhanced the application's design.

\section{FUTURE WORKS}

Based on the discussion above, this research will continuously improve the diverse representation of the microorganism notes, adding more gamification elements, such as group competitions, and setting the application in an iOS platform. At the same time, future research will focus more on the importance of suitable methods and sufficient respondents to evaluate the application. The proper method of evaluation will uncover a significant or insignificant aspect of any application [23], [24], [25].

\section{ACKNOWLEDGMENT}

This study was funded by the Universiti Kebangsaan Malaysia Research Grant (GPK-P\&P-2020-005).

\section{REFERENCES}

[1] Sumintono, B. (2017). Science education in Malaysia: challenges in the 21st century. Jurnal Cakrawala Pendidikan, 36(3).

[2] Nielsen, B. L., Brandt, H. \& Swensen, H. (2016). Augmented reality in science education-affordances for student learning. Nordic Studies in Science Education 12(2): 157. 
[3] Kesim, M. \& Ozarslan, Y. (2012). Augmented Reality in Education: Current Technologies and the Potential for Education. Procedia - Social and Behavioral Sciences 47(222): 297-302.

[4] Salmi, H., Kaasinen, A. \& Kallunki, V. (2012). Towards an Open Learning Environment via Augmented Reality (AR): Visualising the Invisible in Science Centres and Schools for Teacher Education. Procedia - Social and Behavioral Sciences 45: 284-295.

[5] Lu, S.-J., \& Liu, Y.-C. (2015). Integrating augmented reality technology to enhance children's learning in marine education. Environmental Education Research, 21(4), 525-541. doi:10.1080/13504622.2014. 911247.

[6] Weng, C., Otanga, S., Christianto, S. M., \& Chu, R. J.-C. (2019). Enhancing Students' Biology Learning by Using Augmented Reality as a Learning Supplement. Journal of Educational Computing Research, 073563311988421. doi:10.1177/0735633119884213.

[7] Suprapto, N., Nandyansah, W., \& Mubarok, H. (2020). An Evaluation of the "PicsAR" Research Project: An Augmented Reality in Physics Learning. International Journal of Emerging Technologies in Learning (iJET), 15(10), 113-125.

[8] Athauda, G., Toonkel, R. L., \& Kashan, S. B. (2018). Developing a visual learning tool to aid the studying of antimicrobial spectrum of activity. In Proceedings for Annual Meeting of The Japanese Pharmacological Society WCP2018 (The 18th World Congress of Basic and Clinical Pharmacology) (pp. PO1-7). Japanese Pharmacological Society.

[9] Aottiwerch, N., \& Kokaew, U. (2017). Design computer-assisted learning in an online Augmented Reality environment based on Shneiderman's eight Golden Rules. In 2017 14th International Joint Conference on Computer Science and Software Engineering (JCSSE) (pp. 1-5). IEEE.

[10] Avila-Pesantez, D. F., Vaca-Cardenas, L. A., Delgadillo Avila, R., Padilla Padilla, N., \& Rivera, L. A. (2018). Design of an Augmented Reality Serious Game for Children with Dyscalculia: A Case Study. Technology Trends, 165-175. doi:10.1007/978-3-030-05532-5_12.

[11] Plecher, D. A., Eichhorn, C., Kindl, J., Kreisig, S., Wintergerst, M., \& Klinker, G. (2018). Dragon Tale - A Serious Game for Learning Japanese Kanji. Proceedings of the 2018 Annual Symposium on Computer-Human Interaction in Play Companion Extended Abstracts CHI PLAY '18 Extended Abstracts. doi:10.1145/3270316.3271536.

[12] Thongchum, K., \& Charoenpit, S. (2018). A conceptual design of Kanji mobile application with augmented reality technology for beginner. 2018 5th International Conference on Business and Industrial Research (ICBIR). doi:10.1109/icbir.2018.8391183.

[13] Zainal Rasyid Mahayuddin, A F M Saifuddin Saif (2020) Augmented Reality Based AR Alphabets Towards Improved Learning Process in Primary Education System. Journal of Critical Reviews, 7 (19), 514-521. doi:10.31838/jcr.07.19.66.

[14] Ishaq, K., Zin, N. A. M., Rosdi, F., Jehanghir, M., Ishaq, S., \& Abid, A. (2021). Mobile-assisted and gamification-based language learning: a systematic literature review. PeerJ Computer Science, 7, e496.
[15] Kaleel, S. \& Harishankar, S. (2013). Applying Agile Methodology in Mobile Software Engineering: Android Application Development and its Challenges. Computer Science Technical Reports 11.

[16] Knott, D. (2015). Hands-on mobile app testing: a guide for mobile testers and anyone involved in the mobile app business. Addison-Wesley Professional. Hair, J. F., Black, W. C., Babin, B. J., \& Anderson, R. E. (2010). Multivariate data analysis (Seven ed.). Upper Saddle River, NJ Prentice Hall: Pearson. Hair, J. F., Black, W. C., Babin, B. J., \& Anderson, R. E. (2010). Multivariate data analysis (Seven ed.). Upper Saddle River, NJ Prentice Hall: Pearson.

[17] Hair, J. F., Black, W. C., Babin, B. J., \& Anderson, R. E. (2010). Multivariate data analysis (Seven ed.). Upper Saddle River, NJ Prentice Hall: Pearson. Hair, J. F., Black, W. C., Babin, B. J., \& Anderson, R. E. (2010). Multivariate data analysis (Seven ed.). Upper Saddle River, NJ Prentice Hall: Pearson. Hair, J. F., Black, W. C., Babin, B. J., \& Anderson, R. E. (2010). Multivariate data analysis (Seven ed.). Upper Saddle River, NJ Prentice Hall: Pearson.

[18] Fkrudin, A., Yusoff, M., Romli, A. B., Pengajian, J., Politeknik, A. \& Omar, U. (2018). Kebolehgunaan Aplikasi Mudah Alih (Mobile Apps) Bagi Kursus Sains, Teknologi Dan Kejuruteraan Dalam Islam (MIstech) Di Politeknik Malaysia (Usability of Mobile Application (Mobile Apps) in The Course of Science, Technology and Engineering in Islam (M-IST. Malaysian Online Journal of Education 2(1): 18-28.

[19] Ramli, R. Z., Kapi, A. Y., \& Osman, N. (2015). Visualisation makes array easy. In Proceedings of the 2015 International Conference on Testing and Measurement: Techniques and Applications (TMTA'15). CRC Press (pp. 381-384).

[20] Chen, P., Liu, X., Cheng, W., \& Huang, R. (2016). A review of using Augmented Reality in Education from 2011 to 2016. Lecture Notes in Educational Technology, 13-18. doi:10.1007/978-981-10-2419-1_2.

[21] Vlachopoulos, D., \& Makri, A. (2017). The effect of games and simulations on higher education: a systematic literature review. International Journal of Educational Technology in Higher Education, 14(1). doi:10.1186/s41239-017-0062-1.

[22] Alkhattabi, M. (2017). Augmented Reality as E-learning Tool in Primary Schools' Education: Barriers to Teachers' Adoption. International Journal of Emerging Technologies in Learning (iJET), 12(02), 91. doi:10.3991/ijet.v12i02.6158.

[23] Alsubhi, M. A., Sahari, N., \& Wook, T. T. (2020). A Conceptual Engagement Framework for Gamified E-Learning Platform Activities. International Journal of Emerging Technologies in Learning (iJET), 15(22), 4-23.

[24] Khaleel, F. L., Ashaari, N. S., \& Wook, T. S. M. T. (2020). The impact of gamification on students learning engagement. International Journal of Electrical and Computer Engineering, 10(5), 4965.

[25] Zaini, N. A., Noor, S. F. M., \& Wook, T. S. M. T. (2019). The Model of Game-based Learning in Fire Safety for Preschool Children. Editorial Preface From the Desk of Managing Editor, 10(9). 